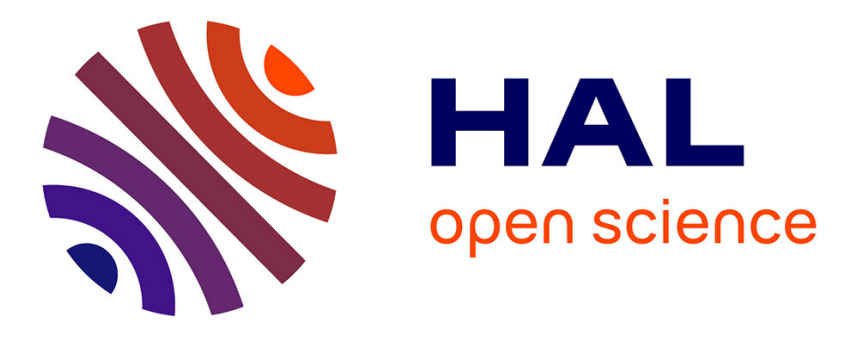

\title{
Brain structural substrates of cognitive procedural learning in alcoholic patients early in abstinence.
}

Ludivine Ritz, Shailendra Segobin, Anne Pascale Le Berre, Coralie Lannuzel, Céline Boudehent, François Vabret, Francis Eustache, Anne Lise Pitel, Hélène Beaunieux

\section{To cite this version:}

Ludivine Ritz, Shailendra Segobin, Anne Pascale Le Berre, Coralie Lannuzel, Céline Boudehent, et al.. Brain structural substrates of cognitive procedural learning in alcoholic patients early in abstinence.. Alcoholism: Clinical and Experimental Research, 2014, 38 (8), pp.2208-16. 10.1111/acer.12486 . inserm-01067948

\section{HAL Id: inserm-01067948 https://www.hal.inserm.fr/inserm-01067948}

Submitted on 24 Sep 2014

HAL is a multi-disciplinary open access archive for the deposit and dissemination of scientific research documents, whether they are published or not. The documents may come from teaching and research institutions in France or abroad, or from public or private research centers.
L'archive ouverte pluridisciplinaire HAL, est destinée au dépôt et à la diffusion de documents scientifiques de niveau recherche, publiés ou non, émanant des établissements d'enseignement et de recherche français ou étrangers, des laboratoires publics ou privés. 


\title{
Brain Structural Substrates of Cognitive Procedural Learning in Alcoholic Patients Early in Abstinence
}

\author{
Ludivine Ritz, Shailendra Segobin, Anne Pascale Le Berre, Coralie Lannuzel, Céline \\ Boudehent, François Vabret, Francis Eustache, Anne Lise Pitel, and Hélène Beaunieux
}

\begin{abstract}
Background: Procedural learning allows for the acquisition of new behavioral skills. Previous studies have shown that chronic alcoholism is characterized by impaired cognitive procedural learning and brain abnormalities affecting regions that are involved in the automation of new cognitive procedures in healthy individuals. The goal of the present study was to investigate the brain structural substrates of cognitive procedural learning in alcoholic patients (ALs) early in abstinence.

Methods: Thirty-one ALs and 31 control participants (NCs) performed the Tower of Toronto task (4 daily learning sessions, each comprising 10 trials) to assess cognitive procedural learning. We also assessed episodic and working memory, executive functions, and visuospatial abilities. ALs underwent 1.5T structural magnetic resonance imaging.

Results: The initial cognitive phase was longer in the AL group than in the NC group, whereas the autonomous phase was shorter. In ALs, the longer cognitive phase was predicted by poorer planning and visuospatial working memory abilities, and by smaller gray matter (GM) volumes in the angular gyrus and caudate nucleus. ALs' planning abilities correlated with smaller GM volume in the angular gyrus.

Conclusions: Cognitive procedural learning was impaired in ALs, with a delayed transition from the cognitive to the autonomous phase. This slowdown in the automation of the cognitive procedure was related to lower planning abilities, which may have hampered the initial generation of the procedure to be learned. In agreement with this neuropsychological finding, a persistent relationship was found between learning performance and the GM volumes of the angular gyrus and caudate nucleus, which are usually regarded as markers of planning and initial learning of the cognitive procedure.
\end{abstract}

Key Words: Procedural Memory, Alcoholism, Structural MRI, Planning, Angular Gyrus.

T HE TREATMENT OF alcohol dependence based on cognitive behavioral therapy requires the planning and automation of new behavioral procedures (Carroll et al., 2011). To prevent relapse and maintain abstinence, alcoholic patients (ALs) have to adopt new behaviors (Kiluk et al., 2011; for a review, see Bates et al., 2013), and this involves the encoding of new procedures in procedural memory. Procedural memory has been defined (Cohen and Squire, 1980) as the memory system in charge of encoding, storing, and retrieving the procedures that underlie motor, verbal, and cognitive skills. Procedural learning needs to be distinguished from implicit learning, where information is acquired unconsciously. During procedural learning, the individual is

From the U1077 ( $L R, S S, A P L B, C L, C B, F V, F E, A L P, H B$ ), INSERM, Caen, France; UMR-S1077 ( $L R, S S, A P L B, C L, C B, F V, F E$, $A L P, H B)$, Université de Caen Basse-Normandie, Caen, France; UMRS1077 ( $L R, S S, A P L B, C L, C B, F V, F E, A L P, H B$ ), Ecole Pratique des Hautes Etudes, Caen, France; Centre Hospitalier Universitaire (LR, SS, $A P L B, C L, C B, F V, F E, A L P, H B)$, Caen, France; and Service d'addictologie $(C B, F V)$, Centre Hospitalier Universitaire, Caen, France.

Received for publication July 27, 2013; accepted April 29, 2014.

Reprint requests: Hélène Beaunieux, UFR de Psychologie, Université de Caen Basse Normandie, Esplanade de la Paix, 14032 Caen Cedex, France; Tel.: + 33 (0)2315656 25; Fax: + 332315656 65; E-mail: helene.beaunieux@unicaen.fr

Copyright (C) 2014 by the Research Society on Alcoholism.

DOI: 10.1111/acer.12486 actively, voluntarily, and consciously engaged in the task. More specifically, a cognitive procedure is a set of organized actions directed toward a goal. For example, learning to drive typically involves cognitive procedural learning. The acquisition of new cognitive skills in procedural memory (i.e., cognitive procedural learning) can be assessed by the Tower of Toronto (TT) or Tower of Hanoi (TH) tasks. When these disk-transfer tasks are used over just a few trials, they primarily measure problem solving and executive functions, whereas when they are practiced over many learning sessions, they measure cognitive procedural learning. Cognitive (Beaunieux et al., 2006) and imaging studies (Hubert et al., 2007) conducted in healthy young individuals have demonstrated the validity of the TT task for assessing the learning and automation of cognitive procedures. A case study involving 2 patients with head injury suggested that performances on the TH task can be predictive of the learning processes involved in programing an electronic organizer (Pitel et al., 2006). However, while several studies have investigated implicit learning, conditioning or priming in alcoholism (Fama et al., 2004, 2006; Hayes et al., 2012), only 2 published studies have explored cognitive procedural learning in ALs using the TT or TH tasks (Beaunieux et al., 2013; Pitel et al., 2007b), and neither included brain imaging.

Compared with other forms of memory, the specificity of procedural memory, according to the Adaptive Control of 
Thoughts model (Anderson, 1982, 1992), is that the encoding of a new cognitive procedure occurs in 3 different successive phases (cognitive, associative, and autonomous), each involving different types of processes (Ackerman and Cianciolo, 2000; Beaunieux et al., 2006; Saint-Cyr et al., 1988; Winter et al., 2001; Woltz, 1988; Xu and Corkin, 2001). Individual performances during the cognitive phase, which is a highly controlled stage, are linked to general intelligence, and episodic and working memory, as well as to executive functions. The autonomous phase is characterized by the intervention of psychomotor abilities and procedural memory per se. The associative phase is regarded as a transitional stage between the 2 others.

A positron emission tomography (PET) activation study conducted in healthy young individuals highlighted a specific brain network underlying TT automation (Hubert et al., 2007). During the cognitive phase, the prefrontal cortices, anterior cingulate gyrus, right angular gyrus, and posterior cerebellar regions were activated. The activation of this frontoparietal network was interpreted as reflecting the involvement of episodic memory (encoding of information), working memory, and executive functions (Fincham et al., 2002; Frey and Petrides, 2000). Furthermore, the activation of the right angular gyrus correlated with the time required to solve the first TT trial, and was attributed to the use of planning abilities. The associative phase was characterized by the activation, among others, of the caudate nucleus, which has also been found to be involved in the automation of a procedure in neuropsychological (Saint-Cyr et al., 1988), neuroimaging (Poldrack et al., 1998; Wan et al., 2012), and motor learning studies (Doyon et al., 2003). This brain structure has been described as playing a role in the acquisition and maintenance of procedures in memory. The activation of occipital regions during both the associative and autonomous phases suggested the intervention of mental imagery. Last, the anterior cerebellum was solely activated during the autonomous phase, which may indicate that performance is mainly determined by psychomotor abilities at that stage.

The brain regions involved in the acquisition of the TT task are known to be damaged by chronic and heavy alcohol consumption (Chanraud et al., 2007; Pitel et al., 2012; Sullivan, 2003), and research has revealed that alcoholism is characterized by cognitive procedural learning impairments (Beaunieux et al., 2013; Pitel et al., 2007b). In these 2 studies, ALs were found to be slower at acquiring a novel cognitive procedure, meaning that even after 40 trials, the procedure was still not yet fully automated. These deficits have been explained by the deleterious effects of chronic alcoholism on episodic memory, working memory, and executive functioning (Ihara et al., 2000; Noël et al., 2012; Pitel et al., 2007a), which need to be intact for a new cognitive procedure to be acquired (Beaunieux et al., 2006). Given the nature of the tasks used to assess cognitive procedural learning, the visuospatial deficits that are frequently reported in alcoholism (Fama et al., 2004) may also explain procedural learning disabilities, at least in part.
Thus, the cognitive procedural learning impairments observed in ALs may result from abnormalities in the brain's frontoparietal and frontocerebellar networks. This study was therefore designed to investigate the brain structural substrates of cognitive procedural learning in ALs early in abstinence. In the light of previous studies (Beaunieux et al., 2013; Pitel et al., 2007b), we expected ALs to display cognitive procedural learning deficits, with a slowdown in the learning dynamics. Accordingly, the cognitive phase would last longer in the ALs than in control participants (NCs), while the autonomous phase would be correspondingly shorter, given the set number of trials administered for the acquisition of the cognitive procedure. Regarding brain volume, we hypothesized that the longer the cognitive phase (i.e., poor procedural learning abilities) the smaller the gray matter (GM) volumes (negative correlation). Given the hypothesized slowdown in the acquisition of the cognitive procedure, we expected to find brain regions regarded as markers of the cognitive phase (i.e., belonging to the frontoparietal network) to be related to learning performances across all 3 learning phases.

\section{MATERIALS AND METHODS}

\section{Participants}

Thirty-one ALs (27 men), 6 of whom had been included in a previous study on alcoholism (Beaunieux et al., 2013), were included in this study. They were recruited by clinicians while they were receiving alcohol withdrawal treatment as inpatients at Caen University Hospital. Our objective was to assess these patients early in abstinence (at treatment entry), at the very point at which they need to acquire new cognitive procedures in order to change their behavior and remain abstinent. All the patients met the alcohol dependence criteria of the DSM-IV (American Psychiatric Association, 2000). Although they were early in abstinence (Table 1), none of them presented any physical symptoms of alcohol withdrawal, as assessed by Cushman's scale (Cushman et al., 1985), at inclusion. They were interviewed to ascertain the duration of alcohol use (in years), alcohol misuse (in years), alcohol dependence (in years), and daily alcohol consumption prior to treatment (in units, a standard drink corresponding to a beverage containing $10 \mathrm{~g}$ of pure alcohol; Table 1). Their age, education (years of schooling), and smoking status are provided in Table 1, together with their scores on the WAIS-III Vocabulary and Matrix Reasoning subtests (Wechsler, 2001), Mini Mental State Examination (MMSE; Folstein et al., 1975), Beck Depression Inventory (Beck et al., 1961), and StateTrait Anxiety Inventory Form Y (Spielberger et al., 1983). As no relationship was found between demographic variables (including sex) and clinical variables (including smoking status), considered separately for ALs and NCs, and cognitive procedural learning, neuropsychological functioning or brain volume, they were not included in subsequent statistical analyses. Measures of overall cognitive functioning (MMSE, WAIS-III Matrix Reasoning and Vocabulary) did not correlate with procedural learning abilities.

For the cognitive explorations, ALs were compared with $31 \mathrm{NCs,}$ (20 men) matched for age and education (Table 1). All NCs were interviewed to ensure that they did not exceed the World Health Organization's recommendations for alcohol consumption (1980) (no more than 21 or 14 weekly standard drinks for men and women, respectively, and no more than 4 standard drinks per occasion).

None of the participants had a history of neurological (head trauma, epilepsy, Wernicke's encephalopathy) or mental (depres- 
Table 1. Main Features of the Participants

\begin{tabular}{|c|c|c|c|}
\hline & Controls & Alcoholic patients & $p$-Value \\
\hline Number & 31 & 31 & \\
\hline Men/women & $20 / 11$ & $27 / 4$ & $0.04^{a *}$ \\
\hline $\begin{array}{l}\text { Age (years) } \\
\text { Range }\end{array}$ & $\begin{array}{l}45.70 \pm 6.14 \\
31 \text { to } 60\end{array}$ & $\begin{array}{l}43.84 \pm 6.91 \\
31 \text { to } 55\end{array}$ & 0.26 \\
\hline $\begin{array}{l}\text { Education } \\
\text { Range }\end{array}$ & $\begin{array}{l}11.55 \pm 3.31 \\
5 \text { to } 18\end{array}$ & $\begin{array}{l}10.48 \pm 2.29 \\
5 \text { to } 15\end{array}$ & 0.15 \\
\hline $\begin{array}{l}\text { WAIS-III Vocabulary } \\
\text { subtest (standard score) }\end{array}$ & $10.10 \pm 1.70$ & $6.71 \pm 2.58$ & $<0.001^{*}$ \\
\hline Range & 7 to 14 & 3 to 13 & \\
\hline $\begin{array}{l}\text { WAIS-III Matrix Reasoning } \\
\text { subtest (standard score) }\end{array}$ & $11.13 \pm 2.17$ & $7.09 \pm 2.34$ & $<0.001^{*}$ \\
\hline Range & 8 to 16 & 3 to 13 & \\
\hline $\begin{array}{l}\text { MMSE } \\
\text { Range }\end{array}$ & $\begin{array}{l}29.54 \pm 0.77 \\
27 \text { to } 30\end{array}$ & $\begin{array}{l}27.29 \pm 1.66 \\
24 \text { to } 30\end{array}$ & $<0.001^{*}$ \\
\hline $\begin{array}{l}\text { Beck Depression Inventory } \\
\text { Range }\end{array}$ & $\begin{array}{l}1.58 \pm 2.00 \\
0 \text { to } 7\end{array}$ & $\begin{array}{l}7.74 \pm 3.49 \\
0 \text { to } 14\end{array}$ & $<0.001^{*}$ \\
\hline \multicolumn{4}{|l|}{$\begin{array}{l}\text { State-Trait Anxiety } \\
\text { Inventory Y Form }\end{array}$} \\
\hline $\begin{array}{l}\text { State anxiety } \\
\text { Range }\end{array}$ & $\begin{array}{l}29.97 \pm 9.84 \\
20 \text { to } 60\end{array}$ & $\begin{array}{l}33.58 \pm 10.12 \\
20 \text { to } 54\end{array}$ & 0.16 \\
\hline $\begin{array}{l}\text { Trait anxiety } \\
\text { Range }\end{array}$ & $\begin{array}{l}33.77 \pm 7.55 \\
21 \text { to } 52\end{array}$ & $\begin{array}{l}49.87 \pm 13.83 \\
22 \text { to } 74\end{array}$ & $<0.001^{*}$ \\
\hline $\begin{array}{l}\text { Smoking status } \\
\text { (no. cigarettes per day) }\end{array}$ & $3.40 \pm 8.38$ & $21.82 \pm 15.38$ & $<0.001^{*}$ \\
\hline Range & 0 to 40 & 0 to 60 & \\
\hline $\begin{array}{l}\text { Days of sobriety } \\
\text { before inclusion }\end{array}$ & - & $12.64 \pm 7.16$ & - \\
\hline Alcohol use (years) & - & $26.68 \pm 7.44$ & - \\
\hline Alcohol misuse (years) & - & $15.71 \pm 10.50$ & - \\
\hline $\begin{array}{l}\text { Alcohol } \\
\text { dependence (years) }\end{array}$ & - & $9.23 \pm 9.32$ & - \\
\hline $\begin{array}{l}\text { Daily alcohol } \\
\text { consumption (units) }\end{array}$ & - & $23.68 \pm 13.69$ & - \\
\hline Number of withdrawals & - & $2.35 \pm 1.47$ & - \\
\hline
\end{tabular}

MMSE, Mini Mental State Examination.

${ }^{\mathrm{a} C h i-s q u a r e .}$

*Significant difference between alcoholic patients and control participants at $p<0.05$ ( $t$-tests).

Data are shown as means \pm standard deviation.

sion, anxiety disorder) illness, or other forms of substance misuse or dependence (except tobacco), and none were under psychotropic medication that might have had an effect on their cerebral or cognitive functioning. All participants were informed about the study prior to their inclusion and provided their written informed consent, and the study was approved by the local ethics committee (CPP Nord Ouest III).

\section{Cognitive Procedural Learning}

Cognitive procedural learning abilities were assessed with the TT task (Saint-Cyr et al., 1988). The material comprises a rectangular base with 3 vertical pegs and 4 different colored disks: 1 black, 1 red, 1 yellow, and 1 white. At the start of the test, the disks are stacked on the leftmost peg, with the darkest disks at the bottom and the lightest ones at the top. The task consists in rebuilding this configuration on the rightmost peg, respecting the following 2 rules: move only 1 disk at a time and never place a darker disk on top of a lighter one. These rules were read out to the participants and explained through examples of authorized and unauthorized moves. Four consecutive daily learning sessions of 10 repeated trials were administered to all participants (Fig. 1). For each trial, we recorded both the time and the number of moves needed to complete the procedure (minimum 15), but only the number of moves was used in the analyses.
We delimited the 3 phases (cognitive, associative, and autonomous) for each participant, based on the number of moves per trial and the 3-stage analysis described by Hubert and colleagues (2007). Briefly, we deemed that participants remained in the cognitive phase until they had found the optimum solution (i.e., 15 moves). The length of the cognitive phase therefore corresponded to the number of trials in which the participant failed to find the optimum solution. The associative phase started with the discovery of the optimum solution (i.e., when the participant first completed the problem in 15 moves). The associative phase only ended when the participant was able to reproduce the optimum solution 5 times in a row. Thus, the length of the associative phase corresponded to the number of trials during which the participant solved the procedure in around 15 moves. The procedure was not completely mastered during the associative phase, and some errors were always present. Participants were deemed to be in the autonomous phase when they were able to reproduce the optimum solution 5 times in a row. However, 1 error among 75 consecutive moves (i.e., 5 trials $\times 15$ moves) was allowed.

\section{Neuropsychological Assessment}

Participants underwent a battery of neuropsychological tests to assess their episodic memory, working memory, executive functions, and visuospatial abilities. The rationale behind the selection of these neuropsychological measures was that (i) they are sensitive to the effects of chronic alcohol consumption (Le Berre et al., 2010; Noël et al., 2012; Pitel et al., 2007a; Sullivan et al., 2000), (ii) they correlate with procedural learning performance during the cognitive phase (Beaunieux et al., 2006; Hubert et al., 2007; Pitel et al., 2007b), and (iii) some of them had been used in previous studies to examine the relationship between procedural learning and neuropsychological abilities (Trail Making Test [TMT], backward visuospatial span; Beaunieux et al., 2013; Pitel et al., 2007b).

Episodic Memory. The French version of the Free and Cued Selective Reminding Test (Grober and Buschke, 1987; der Linden and GREMEM group, 2004) was used to assess episodic memory. The first phase of this test consisted in encoding 16 words belonging to 16 different semantic categories. The words were printed 4 to a sheet ( 1 word in each quadrant), and participants had to point to each word when they heard its relevant semantic category. For example, when the "science" category was provided by the experimenter, participants had to point to "geography." Every 4 words, they had to perform immediate cued recall using semantic category cues, to ensure that encoding had taken place. If the participants failed, the experimenter showed them the sheet again so that all 16 items were eventually retrieved at immediate cued recall. This encoding phase was followed by 3 recall trials (each comprising free recall and, if necessary, categorical cued recall). Between each trial, participants were asked to count backward for 20 seconds. We chose to use 3 free recall trials to assess learning abilities as these are assumed to be sensitive to deficits in ALs (Weingartner et al., 1996).

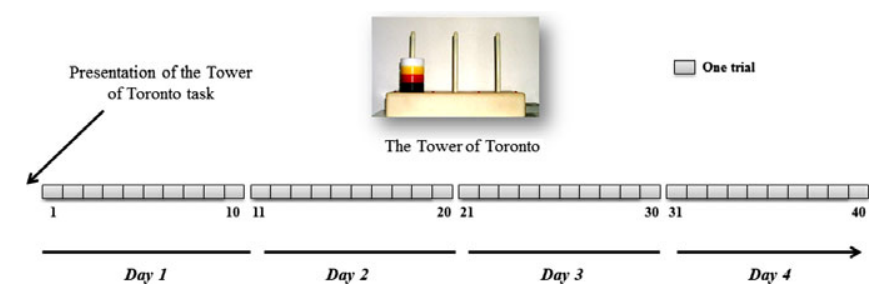

Fig. 1. Design of the assessment of cognitive procedural learning with the Tower of Toronto (TT) task. Rules were read out and explained to participants on the first day. All participants underwent 4 consecutive daily learning sessions, each comprising 10 consecutive trials. 
Working Memory and Executive Functions. The slave systems of working memory (phonological loop and visuospatial sketchpad) were respectively assessed with the verbal and visuospatial forward spans of the WAIS-III (raw scores converted to standard scores; Wechsler, 2001). The manipulation of information stored in working memory was assessed with the verbal and visuospatial backward spans of the WAIS-III (standard scores; Wechsler, 2001).

Flexibility was assessed with the GREFEX version of the TMT (Reitan, 1955). The TMT is a reactive mental flexibility task that comes in 2 parts. In Part A, participants have to join the numbers 1 to 25 up on a sheet of paper as quickly as possible. In Part B, they have to join numbers and letters up in an alternating pattern (1-A-2B-3-C, etc.) as quickly as possible. The time taken to complete Part $\mathrm{B}$ was used as an indicator of flexibility.

Planning was assessed with the number of moves required to solve the first trial of the TT task.

Visuospatial Abilities. Visuospatial abilities were assessed by the copy accuracy of the Rey Osterrieth Complex Figure (ROCF; Osterrieth, 1944; max. score 36).

\section{Magnetic Resonance Imaging}

Anatomical Image Acquisition. ALs underwent a high-resolution volumetric T1-weighted magnetic resonance imaging (MRI) scan (1.5T Signa Advantage Echo Speed; GE Healthcare, Milwaukee, WI) which consisted of a set of 128 adjacent axial slices parallel to the anterior commissure-posterior commissure (AC-PC) line, with a slice thickness of $1.5 \mathrm{~mm}$ and a voxel size of $0.94 \times 0.94 \mathrm{~mm}$. We used a spoiled gradient echo sequence $\mathrm{TR}=1.03 \mathrm{~ms}$; echo time $\mathrm{TE}=2.1 \mathrm{~ms}$; field of view $=24 \times 18 \mathrm{~cm}$; matrix $=256 \times 192$.

Preprocessing of Anatomical Images. MRI data sets were preprocessed using the VBM5 toolbox (http://dbm.neuro.uni-jena.de/ vbm/vbm5-for-spm5/) implemented in Statistical Parametric Mapping 5 software (SPM5; Wellcome Department of Cognitive Neurology, Institute of Neurology, London, UK). Raw MRI data were spatially normalized to Montreal Neurological Institute (MNI) space $\left(\right.$ voxel size $=1 \mathrm{~mm}^{3}$; matrix $\left.=156 \times 189 \times 157\right)$ and segmented into GM, white matter, and cerebrospinal fluid. The normalized GM images were modulated by the Jacobian determinants to correct for nonlinear warping only, so that the resulting brain volumes were corrected for brain size (Chételat et al., 2012). The resulting images were smoothed with a Gaussian kernel of $10 \mathrm{~mm}$ full width at half maximum.

Data Masking. The GM mask was obtained by averaging the GM images of 25 age-matched NCs (drawn from our data base) in MNI space. This average image was then thresholded at 0.5 to obtain the binary GM mask. The latter was applied to the ALs' smoothed data for statistical analysis.

\section{Statistical Analysis}

We used $t$-tests to compare the 2 groups (AL and NC) on the length of the cognitive procedural learning phase (in number of trials), and analyzed the number of moves required to solve the task to examine the dynamics of learning (Beaunieux et al., 2013; Hubert et al., 2007).

We used $t$-tests to compare the 2 groups on episodic memory, working memory, executive functions, and visuospatial abilities. Within each group, we calculated Pearson correlation coefficients to identify the relationship between the length of each learning phase (in number of trials) and episodic memory, working memory, executive functions, and visuospatial abilities. According to the correlations we observed, we then ran forward stepwise regression analyses to identify the best predictors of the length of each learning phase.
In the AL group, voxel-based multiple regressions between the length of each learning phase (in number of trials) and GM volumes were performed in SPM5 at $p<0.001$ (uncorrected for multiple comparisons) and using an extent threshold of $\mathrm{k}=200$ voxels. GM anatomical localization was carried out using automated anatomical labeling software implemented in SPM5 (Tzourio-Mazoyer et al., 2002) and verified using the Harvard-Oxford cortical and subcortical structural atlases implemented in FSL (http://fsl.fmrib.ox. ac.uk/fsl/fs14.0/fslview/atlas-descriptions.html\#ho).

Finally, Pearson correlation coefficients and regression analyses were carried out between the neuropsychological predictors of the length of each learning phase and the GM volumes of the brain regions related to cognitive procedural learning.

Only results with $p<0.05$ are shown, and those that were still significant after Bonferroni correction are provided in the tables. Nonparametric analyses were used to confirm the results yielded by the parametric statistics. We chose to use parametric statistics to perform the stepwise regression analyses, as no nonparametric test is currently available.

\section{RESULTS}

\section{Dynamics of the Cognitive Procedural Learning}

We found a significant effect of group, $t(60)=2.22$, $p=0.03$, for the length of the cognitive phase, as this phase was longer for the AL group $(9.74 \pm 10.76$ trials, range 0 to 40) than for the NC group (5.06 \pm 4.60 trials, range 0 to 23$)$. The length of the associative phase did not differ between the 2 groups (AL: $20.32 \pm 2.10$ trials, range 0 to 39 ; $\mathrm{NC}$ : $17.48 \pm 11.75$ trials, range 0 to $39 ; t(60)=0.95, p=0.34)$. The autonomous phase was shorter for the AL group (9.94 \pm 11.37 trials, range 0 to 31$)$ than for the NC group $(17.45 \pm 11.57$ trials, range 0 to $39 ; t(60)=-2.58, p=0.01$; Fig. 2).

\section{Neuropsychological Profile of the Alcoholic Group}

ALs performed more poorly than NCs on learning in the episodic memory task $(p<0.001)$ and on the backward vi-

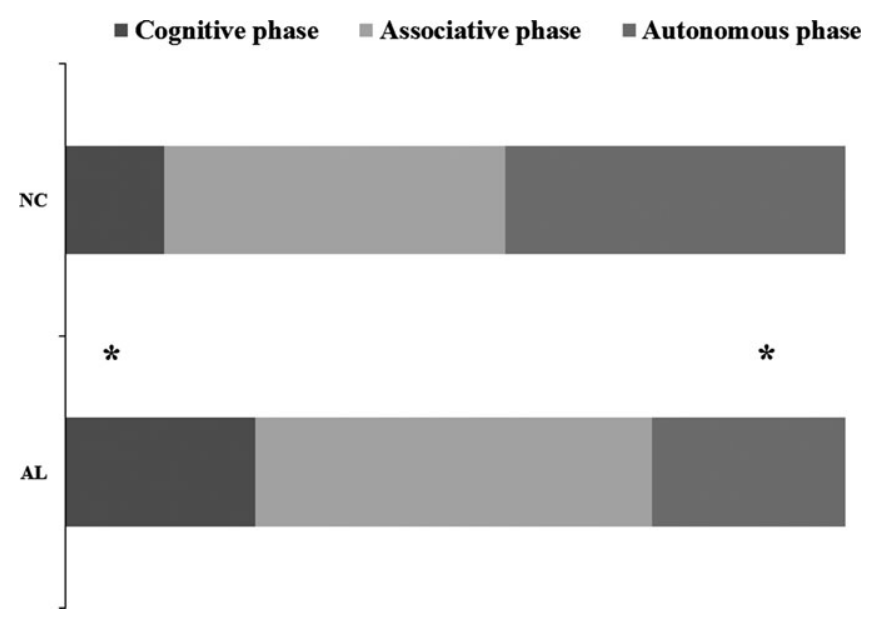

Fig. 2. Length of the 3 learning phases (number of trials) for the alcoholic patients (ALs) and control subjects (NCs). *Significant effect of group at $p<0.05$. 
suospatial span $(p<0.001)$. Regarding executive functions, ALs tended to differ from NCs on the TMT Part B $(p=0.051)$, but there was no significant difference in the number of moves required to solve the first trial of the TT task $(p=0.90)$. Nor did the 2 groups differ on ROCF copy accuracy $(p=0.36$; Table 2$)$.

\section{Correlations Between Cognitive Procedural Learning and Neuropsychological Measures}

In the NC group, there was no correlation between the length of the learning phases and any of the neuropsychological measures $(p>0.05)$. Scatterplots (data not shown) suggested little variability in performances.

In the AL group, the length of the cognitive phase correlated with performance on the backward visuospatial span $(r=-0.41, p=0.02)$, TMT Part B $(r=0.41, p=0.02)$, ROCF copy accuracy $(r=-0.38, p=0.04)$, and the number of moves in the first trial of the TT task $(r=0.44, p=0.01)$. There was no relationship between the length of the associative and autonomous phases and the neuropsychological measures. The results are set out in Table 3 .

The best cognitive predictors of the length of the cognitive phase in the AL group were the number of moves in the first trial of the TT task and the backward visuospatial span, which together accounted for $37 \%$ of the variance $(p=0.002$; Table 4).

\section{Brain Structural Substrates of Cognitive Procedural Learning in the Alcoholic Group}

Regression analyses revealed a negative correlation between the length of the learning phases and GM volumes, in that the longer the cognitive phase (i.e., the poorer the procedural learning abilities), the smaller the GM volumes in the right angular gyrus, the caudate nucleus and anterior cingular cortex bilaterally, and the left frontal gyrus (Table 5).

As expected, no positive correlation was found between the length of the cognitive phase and GM volumes.

Neither positive nor negative correlations was found between the length of the associative phase and GM volumes (Table 5).
Significant positive correlations were, however, found for the autonomous phase, in that the longer the phase (i.e., the better the procedural learning abilities), the larger the GM volumes in the bilateral fusiform and temporal gyrus, bilateral caudate nucleus, right angular gyrus, left calcarine sulcus regions (including the lingual gyrus and cerebellar lobule VI and Crus I) and left thalamus (Table 5). No negative correlation was found between the length of the autonomous phase and GM volumes.

\section{Relationships Between Neuropsychological Predictors and Brain Structural Substrates of Cognitive Procedural Learning}

Regarding the best cognitive predictors of the length of the cognitive phase, only the number of moves required to solve the first trial of the TT task negatively correlated with GM volume in the right angular gyrus $(r=-0.57, p=0.001)$ and left caudate nucleus $(r=-0.47, p=0.008)$. Regression analyses showed that the GM volume of the right angular gyrus was the sole predictor of the number of moves in the first trial of the TT task $(\beta=-0.57, p<0.001)$, accounting for $32 \%$ of the variance (Fig. 3).

\section{DISCUSSION}

The aim of this study was to investigate the brain structural substrates of cognitive procedural learning in ALs with a classic profile of impaired episodic and working memory (Ihara et al., 2000; Pitel et al., 2007a). Our behavioral results corroborated the findings of previous studies showing impaired cognitive procedural learning abilities in ALs (Beaunieux et al., 2013; Pitel et al., 2007b). Although it was possible for ALs to acquire the cognitive procedure, they required more trials than the NCs did. The cognitive phase therefore lasted longer for ALs than for NCs, and the autonomous phase was correspondingly shorter, owing to the finite number of trials (40) allowed for the automation of the procedure. As had been reported in a previous study conducted in healthy NCs, ALs, and patients with Korsakoff's syndrome (Beaunieux et al., 2013), the associative phase was preserved in ALs. Impaired cognitive procedural learning in alcoholic individuals may therefore be primarily the conse-

Table 2. Comparison of Episodic Memory, Working Memory, Executive Functions, and Visuospatial Abilities in the Control Participants and Alcoholic Patients

\begin{tabular}{llcr}
\hline Cognitive functions & \multicolumn{1}{c}{ Tasks } & Controls $(n=31)$ & Alcoholic patients $(n=31)$ \\
\hline Episodic memory & Sum of the 3 free recalls (learning) & $34.58 \pm 4.06$ & $30.10 \pm 5.06$ \\
Working memory and & Backward visuospatial span & $5.58 \pm 0.92$ & $4.61 \pm 0.99$ \\
executive functions & TMT Part B & $63.52 \pm 20.63$ & $78.00 \pm 34.67$ \\
\multirow{2}{*}{ Visuospatial abilities } & Number of moves (first trial of TT task) & $24.55 \pm 10.39$ & $24.25 \pm 7.13$ \\
& ROCF copy accuracy & $35.10 \pm 1.85$ & $34.52 \pm 3.01$ \\
\hline
\end{tabular}

TMT, Trail Making Test; TT, Tower of Toronto; ROCF, Rey Osterrieth Complex Figure.

"Significant difference ( $t$-tests) between alcoholic patients and control participants at $p<0.05$ and still significant after Bonferroni correction $(p<0.01)$.

Data are shown as means \pm standard deviation. 
Table 3. Correlations Between Learning Performance and Neuropsychological Measures in the Alcoholic Group

\begin{tabular}{lccc}
\hline Predictive variables & $\begin{array}{c}\text { Cognitive } \\
\text { phase }\end{array}$ & $\begin{array}{c}\text { Associative } \\
\text { phase }\end{array}$ & $\begin{array}{c}\text { Autonomous } \\
\text { phase }\end{array}$ \\
\hline $\begin{array}{l}\text { Episodic memory } \\
\text { Sum of the 3 free } \\
\quad \text { recall trials (learning) }\end{array}$ & 0.004 & -0.28 & 0.29 \\
$\begin{array}{l}\text { Working memory and } \\
\text { executive functions }\end{array}$ & & & \\
$\quad$ Backward visuospatial span & $-0.41^{*}$ & 0.18 & 0.20 \\
$\quad$ TMT Part B & $0.41^{*}$ & 0.28 & 0.11 \\
$\quad$ Number of moves & $0.44^{*, a}$ & -0.14 & -0.27 \\
$\quad$ (first trial of TT task) & & & \\
Visuospatial abilities & & & \\
ROCF copy accuracy & $-0.38^{*}$ & 0.07 & 0.28 \\
\hline
\end{tabular}

TMT, Trail Making Test; TT, Tower of Toronto; ROCF, Rey Osterrieth Complex Figure.

*Significant correlations (Pearson's $r$ ) at $p<0.05$.

${ }^{a}$ Still significant after Bonferroni correction $(p<0.01)$.

Table 4. Best Cognitive Predictors of the Length of the Cognitive Phase of Cognitive Procedural Learning in the Alcoholic Group

\begin{tabular}{lccc}
\hline & $\beta$ & $R^{2}$ & $p$ \\
\hline $\begin{array}{l}\text { Step 1 } \\
\text { Number of moves } \\
\quad \text { (first trial of TT task) }\end{array}$ & 0.44 & 0.19 & $0.01^{\mathrm{a}}$ \\
$\begin{array}{l}\text { Step 2 } \\
\quad \text { Number of moves } \\
\text { (first trial of TT task) }\end{array}$ & 0.44 & 0.37 & 0.006 \\
$\quad \begin{array}{l}\text { Backward } \\
\text { visuospatial span }\end{array}$ & -0.42 & & 0.009 \\
\hline
\end{tabular}

TT, Tower of Toronto.

${ }^{a}$ Still significant after Bonferroni correction $(p<0.01)$.

Only predictors significant at $p<0.05$ (forward stepwise regression analyses) are reported. quence of a delayed transition from the cognitive phase to the later stages of learning (Beaunieux et al., 2013).

As has already been suggested, these cognitive procedural learning disabilities could be explained by alcohol-related visual working memory deficits (Pitel et al., 2007b). A previous study had shown that working memory deficits may prevent ALs from successfully completing the cognitive and associative phases, and thus from automating the cognitive procedure (Pitel et al., 2007b). In this study, regression analyses conducted in the AL group showed that the length of the cognitive phase was predicted by planning abilities and visual working memory. Although the ALs as a group did not differ from NCs on the number of moves required to solve the first trial of the TT task, patients with poorer planning abilities remained in the cognitive phase for longer. In addition, visual working memory deficits may have made it difficult to maintain the optimum solution in memory, either in the course of a trial or from one trial to the next. These findings suggest that the combination of poorer planning abilities and visual working memory deficits delays the transition from the cognitive phase to the later stages, and ultimately hampers the acquisition of new cognitive procedures. The absence of any correlation between the length of the associative phase and neuropsychological measures could be related to the nature of this stage, which is regarded as a default phase of learning between the cognitive and autonomous phases with no specific cognitive determinant. Moreover, there was considerable variability in learning performances during the cognitive phase, but this decreased in the associative phase (data not shown). The low variability in the associative phase may also explain the absence of correlations between the length of this phase and neuropsychological measures.

Table 5. Regression Analyses Between the Length of the Cognitive Procedural Learning Phases and Gray Matter Volume in the Alcoholic Group

\begin{tabular}{|c|c|c|c|c|c|c|}
\hline \multirow[b]{2}{*}{ Regional cluster } & \multirow[b]{2}{*}{ Side } & \multirow[b]{2}{*}{ Cluster size (number of voxels) } & \multirow[b]{2}{*}{$z$-score } & \multicolumn{3}{|c|}{ MNI coordinates of peak voxel } \\
\hline & & & & $x$ & y & z \\
\hline \multicolumn{7}{|l|}{ Cognitive phase $^{a}$} \\
\hline Angular gyrus & Right & 2031 & 4.73 & 32 & -83 & 30 \\
\hline \multirow[t]{2}{*}{ Caudate nucleus } & Left & 1535 & 4.52 & -14 & 20 & -2 \\
\hline & Right & 2366 & 4.27 & 14 & 20 & 1 \\
\hline \multirow[t]{2}{*}{ Anterior cingulate cortex } & Left & 1747 & 3.84 & -6 & 45 & 16 \\
\hline & Right & 1162 & 3.84 & 5 & 41 & 27 \\
\hline Frontal gyrus & Left & 620 & 3.70 & -4 & 67 & 0 \\
\hline Associative phase & \multicolumn{6}{|c|}{ No suprathreshold clusters } \\
\hline \multicolumn{7}{|l|}{ Autonomous phase } \\
\hline \multirow[t]{2}{*}{ Fusiform and temporal gyri } & Right & 496 & 4.27 & 50 & -30 & -25 \\
\hline & Left & 1193 & 3.95 & -45 & -40 & -24 \\
\hline \multirow{2}{*}{ Caudate nucleus } & Left & 725 & 4.20 & -10 & 19 & -3 \\
\hline & Right & 208 & 3.67 & 6 & 17 & -1 \\
\hline Angular gyrus & Right & 597 & 3.93 & 26 & -63 & 45 \\
\hline Calcarine sulcus & Left & 527 & 3.82 & -7 & -86 & -15 \\
\hline \multicolumn{7}{|l|}{$\begin{array}{l}\text { Lingual gyrus } \\
\text { Cerebellar lobule VI, Crus I }\end{array}$} \\
\hline Thalamus & Left & 326 & 3.67 & -10 & -33 & 4 \\
\hline
\end{tabular}

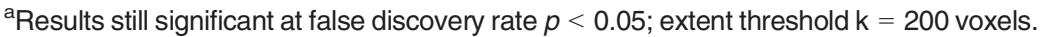

Results are reported at $p<0.001$ (uncorrected); extent threshold $\mathrm{k}=200$ voxels. 


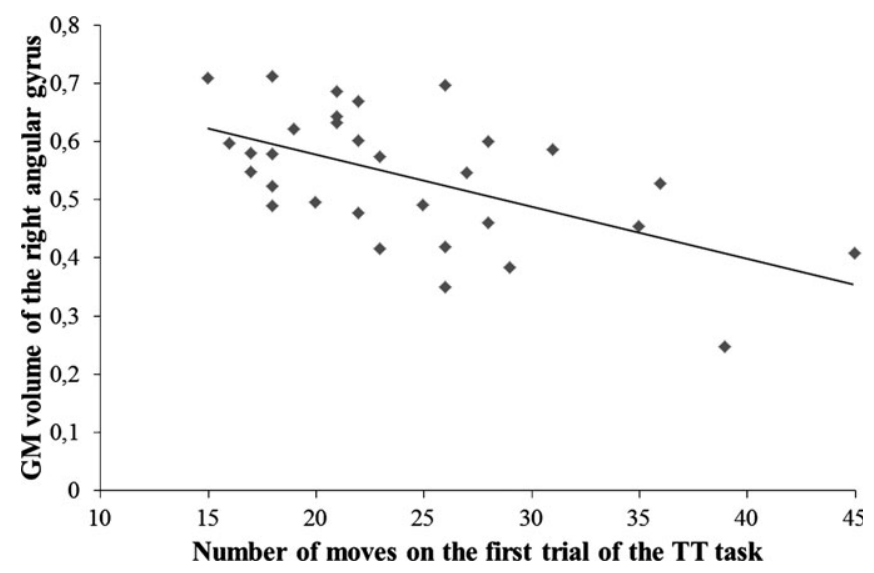

Fig. 3. Relationship between the number of moves in the first trial of the Tower of Toronto (TT) task (planning abilities) and gray matter (GM) volume in the right angular gyrus.

Cognitive procedural learning in ALs is related to GM volume in the brain regions recruited by healthy individuals during cognitive procedural learning (Hubert et al., 2007). In the present investigation, a longer cognitive phase correlated with limited GM volume in the frontoparietal network (frontal cortices, anterior cingulate cortex, and angular gyrus) and caudate nucleus. A shorter autonomous phase correlated with larger GM volume in posterior brain regions (temporal and occipital gyri and cerebellum), as well as the caudate nucleus, angular gyrus, and thalamus. The overall similarity between the structural substrates of cognitive procedural learning identified in alcoholism in this study and the functional substrates found in healthy NCs in a PET activation study (Hubert et al., 2007) lends weight to our interpretation of these brain-behavior relationships.

The caudate nucleus and angular gyrus, whose GM volumes correlated with learning performance not just in the cognitive phase, but also in the autonomous one, can be regarded as key regions for cognitive procedural learning in alcoholism. As these regions are specifically involved in the early stages of learning in NCs (Hubert et al., 2007), the mirror effect we observed here may indicate that ALs did not fully automate the cognitive procedure within the 40 trials, even though they were able to reach the autonomous phase, as defined by our criteria. No correlation was found between the length of the autonomous phase and the cognitive functions assessed in the present investigation. The prolonged relationship with the volumes of the caudate nucleus and angular gyrus therefore points to the prolonged relationship of cognitive processes that were not assessed in our study. In addition to planning, these regions have been found to be involved in attentional processes (Cabeza et al., 2008), the integration of information in memory (Seghier, 2013), and inhibition (Alexander et al., 1986; Grahn et al., 2008).

In a PET activation study conducted in healthy participants (Hubert et al., 2007), the caudate was specifically activated in the associative phase. This activation was attributed to the acquisition and maintenance of the cognitive proce- dure to be automated (Poldrack et al., 1998; Wan et al., 2012). Neuropsychological studies conducted in patients with either Parkinson's or Huntington's disease, both characterized by major caudate nucleus abnormalities, have shown that these patients are impaired on tasks requiring the selection of appropriate subgoals to achieve an action whose outcomes are known (Grahn et al., 2008). This affects their ability to plan and generate the procedure's optimum solution (Saint-Cyr et al., 1988; Schmidtke et al., 2002; Schneider, 2007). In our AL sample, correlations calculated between the cognitive predictors of the length of the cognitive phase and caudate GM volume revealed that planning abilities were linked to GM volume in this region. This result reinforces the assumption that, in ALs, the cognitive phase relates to planning strategies (Fig. 4).

Regression analyses showed that the sole predictor of planning was the GM volume of the angular gyrus. This finding is in line with several PET and functional MRI studies. In healthy individuals, the angular gyrus has been found to play a critical role in the cognitive phase of procedural learning (Hubert et al., 2007), its activation reflecting the use of planning and problem solving when individuals are trying to generate the cognitive procedure (Anderson et al., 2005; Fincham et al., 2002; Seghier, 2013). Thus, in the ALs included in our study, the limited volume of the angular gyrus potentially explains the difficulty they had planning the cognitive procedure.

This study had several limitations. No imaging data were available for the NCs who performed the procedural learning test. As there was no variability in their cognitive performances, we assumed that there would be no variability in brain regression analyses for this group. We therefore based our interpretations on data yielded by a previous PET activation study conducted in healthy participants with the same paradigm (Hubert et al., 2007), bearing in mind that the regression analyses we used in this study are only indirect measures of the brain structural substrates of cognitive per-

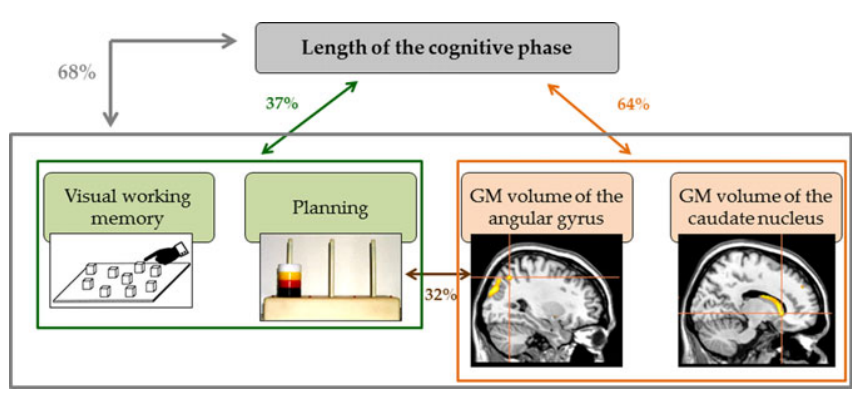

Fig. 4. Summary of the correlations between neuropsychological scores and brain structural substrates of cognitive procedural learning in alcoholic patients. Both visual working memory and planning (in green) and gray matter (GM) volumes of the angular gyrus and caudate nucleus (in orange) predicted the length of the cognitive phase, accounting for 37 and $64 \%$ of the variance, respectively. Planning abilities were related to the volume of the angular gyrus (32\%). When all the neuropsychological and brain structural predictors were included in a single regression analysis, they explained $68 \%$ of the length of the cognitive phase (in gray). 
formances. Finally, the ALs in our sample were included early in abstinence. Therefore, our findings cannot be generalized to the overall population of alcoholic individuals.

To conclude, our results confirm that cognitive procedural learning impairments in ALs are characterized by a delayed transition from the cognitive to the autonomous phase (Beaunieux et al., 2013). This slowdown may be due to difficulty generating the procedure to be automated and maintaining it over the course of the learning session. In agreement with this neuropsychological finding, we found a persistent relationship between performance and the GM volume of the angular gyrus and caudate nucleus, which are usually regarded as markers of planning and initial learning of the cognitive procedure.

\section{ACKNOWLEDGMENTS}

This study was supported by the French National Institute for Health and Medical Research (INSERM) (grant no. R07012EE) and the French National Agency for Research (ANR) Postdoc Return (Retour Post-Doctorants, PDOC) program.

\section{REFERENCES}

Ackerman PL, Cianciolo AT (2000) Cognitive, perceptual-speed, and psychomotor determinants of individual differences during skill acquisition. $\mathbf{J}$ Exp Psychol Appl 6:259-290.

Alexander GE, DeLong MR, Strick PL (1986) Parallel organization of functionally segregated circuits linking basal ganglia and cortex. Annu Rev Neurosci 9:357-381.

American Psychiatric Association (2000) Diagnostic and Statistical Manual of Mental Disorders. 4th ed. DSM-IV-TR ${ }^{\circledR}$. American Psychiatric Association, Washington, DC.

Anderson JR (1982) Acquisition of cognitive skill. Psychol Rev 89:369.

Anderson JR (1992) Automaticity and the ACT* theory. Am J Psychol 105:165-180.

Anderson JR, Albert MV, Fincham JM (2005) Tracing problem solving in real time: fMRI analysis of the subject-paced Tower of Hanoi. J Cogn Neurosci 17:1261-1274.

Bates ME, Buckman JF, Nguyen TT (2013) A role for cognitive rehabilitation in increasing the effectiveness of treatment for alcohol use disorders. Neuropsychol Rev 23:27-47.

Beaunieux H, Hubert V, Witkowski T, Pitel A-L, Rossi S, Danion J-M, Desgranges B, Eustache F (2006) Which processes are involved in cognitive procedural learning? Memory 14:521-539.

Beaunieux H, Pitel AL, Witkowski T, Vabret F, Viader F, Eustache F (2013) Dynamics of the cognitive procedural learning in alcoholics with Korsakoff's syndrome. Alcohol Clin Exp Res 37:1025-1032.

Beck AT, Ward CH, Mendelson M, Mock J, Erbaugh J (1961) An inventory for measuring depression. Arch Gen Psychiatry 4:561-571.

Cabeza R, Ciaramelli E, Olson IR, Moscovitch M (2008) The parietal cortex and episodic memory: an attentional account. Nat Rev Neurosci 9:613625.

Carroll KM, Kiluk BD, Nich C, Babuscio TA, Brewer JA, Potenza MN, Ball SA, Martino S, Rounsaville BJ, Lejuez CW (2011) Cognitive function and treatment response in a randomized clinical trial of computerbased training in cognitive-behavioral therapy. Subst Use Misuse 46:23-34.

Chanraud S, Martelli C, Delain F, Kostogianni N, Douaud G, Aubin H-J, Reynaud M, Martinot J-L (2007) Brain morphometry and cognitive per- formance in detoxified alcohol-dependents with preserved psychosocial functioning. Neuropsychopharmacology 32:429-438.

Chételat G, Villemagne VL, Villain N, Jones G, Ellis KA, Ames D, Martins RN, Masters CL, Rowe CC (2012) Accelerated cortical atrophy in cognitively normal elderly with high $\beta$-amyloid deposition. Neurology 78:477484.

Cohen NJ, Squire LR (1980) Preserved learning and retention of patternanalyzing skill in amnesia: dissociation of knowing how and knowing that. Science 210:207-210.

Cushman P Jr, Forbes R, Lerner W, Stewart M (1985) Alcohol withdrawal syndromes: clinical management with lofexidine. Alcohol Clin Exp Res 9:103-108.

Doyon J, Penhune V, Ungerleider LG (2003) Distinct contribution of the cortico-striatal and cortico-cerebellar systems to motor skill learning. Neuropsychologia 41:252-262.

Fama R, Pfefferbaum A, Sullivan EV (2004) Perceptual learning in detoxified alcoholic men: contributions from explicit memory, executive function, and age. Alcohol Clin Exp Res 28:1657-1665.

Fama R, Pfefferbaum A, Sullivan EV (2006) Visuoperceptual learning in alcoholic Korsakoff syndrome. Alcohol Clin Exp Res 30:680-687.

Fincham JM, Carter CS, van Veen V, Stenger VA, Anderson JR (2002) Neural mechanisms of planning: a computational analysis using event-related fMRI. Proc Natl Acad Sci U S A 99:3346-3351.

Folstein MF, Folstein SE, McHugh PR (1975) "Mini-mental state". A practical method for grading the cognitive state of patients for the clinician. J Psychiatr Res 12:189-198.

Frey S, Petrides M (2000) Orbitofrontal cortex: a key prefrontal region for encoding information. Proc Natl Acad Sci U S A 97:8723-8727.

Grahn JA, Parkinson JA, Owen AM (2008) The cognitive functions of the caudate nucleus. Prog Neurobiol 86:141-155.

Grober E, Buschke H (1987) Genuine memory deficits in dementia. Dev Neuropsychol 3:13-36.

Hayes SM, Fortier CB, Levine A, Milberg WP, McGlinchey R (2012) Implicit memory in Korsakoff's syndrome: a review of procedural learning and priming studies. Neuropsychol Rev 22:132-153.

Hubert V, Beaunieux H, Chételat G, Platel H, Landeau B, Danion J-M, Viader F, Desgranges B (2007) The dynamic network subserving the three phases of cognitive procedural learning. Hum Brain Mapp 28:1415-1429.

Ihara H, Berrios GE, London M (2000) Group and case study of the dysexecutive syndrome in alcoholism without amnesia. J Neurol Neurosurg Psychiatry 68:731-737.

Kiluk BD, Nich C, Carroll KM (2011) Relationship of cognitive function and the acquisition of coping skills in computer assisted treatment for substance use disorders. Drug Alcohol Depend 114:169-176.

Le Berre A-P, Pinon K, Vabret F, Pitel A-L, Allain P, Eustache F, Beaunieux $\mathrm{H}$ (2010) Study of metamemory in patients with chronic alcoholism using a feeling-of-knowing episodic memory task. Alcohol Clin Exp Res 34:1888-1898.

der Linden MV, GREMEM group (2004) L'évaluation des Troubles de la Mémoire : Présentation de Quatre tests de mémoire Épisodique. Solal, Marseilles.

Noël X, Van der Linden M, Brevers D, Campanella S, Hanak C, Kornreich C, Verbanck P (2012) The contribution of executive functions deficits to impaired episodic memory in individuals with alcoholism. Psychiatry Res 198:116-122.

Osterrieth PA (1944) Le test de copie d'une figure complexe; contribution à l'étude de la perception et de la mémoire. [Test of copying a complex figure; contribution to the study of perception and memory]. Arch Psychol 30:206-356.

Pitel AL, Beaunieux H, Lebaron N, Joyeux F, Desgranges B, Eustache F (2006) Two case studies in the application of errorless learning techniques in memory impaired patients with additional executive deficits. Brain Inj 20:1099-1110.

Pitel AL, Beaunieux H, Witkowski T, Vabret F, Guillery-Girard B, Quinette P, Desgranges B, Eustache F (2007a) Genuine episodic memory deficits 
and executive dysfunctions in alcoholic subjects early in abstinence. Alcohol Clin Exp Res 31:1169-1178.

Pitel A-L, Chételat G, Le Berre AP, Desgranges B, Eustache F, Beaunieux H (2012) Macrostructural abnormalities in Korsakoff syndrome compared with uncomplicated alcoholism. Neurology 78:1330-1333.

Pitel AL, Witkowski T, Vabret F, Guillery-Girard B, Desgranges B, Eustache F, Beaunieux H (2007b) Effect of episodic and working memory impairments on semantic and cognitive procedural learning at alcohol treatment entry. Alcohol Clin Exp Res 31:238-248.

Poldrack RA, Desmond JE, Glover GH, Gabrieli JD (1998) The neural basis of visual skill learning: an fMRI study of mirror reading. Cereb Cortex 8: $1-10$.

Reitan RM (1955) The relation of the trail making test to organic brain damage. J Consult Psychol 19:393-394.

Saint-Cyr JA, Taylor AE, Lang AE (1988) Procedural learning and neostriatal dysfunction in man. Brain 111(Pt 4):941-959.

Schmidtke K, Manner H, Kaufmann R, Schmolck H (2002) Cognitive procedural learning in patients with fronto-striatal lesions. Learn Mem 9:419429.

Schneider JS (2007) Behavioral persistence deficit in Parkinson's disease patients. Eur J Neurol 14:300-304.

Seghier ML (2013) The angular gyrus: multiple functions and multiple subdivisions. Neuroscientist 19:43-61.

Spielberger CD, Gorsuch RL, Lushene R, Vagg PR, Jacobs GA (1983) Manual for the State-Trait Anxiety Inventory (Form Y). Consulting Psychologists Press, Palo Alto, CA.

Sullivan EV (2003) Compromised pontocerebellar and cerebellothalamocortical systems: speculations on their contributions to cognitive and motor impairment in nonamnesic alcoholism. Alcohol Clin Exp Res 27:14091419.

Sullivan EV, Rosenbloom MJ, Pfefferbaum A (2000) Pattern of motor and cognitive deficits in detoxified alcoholic men. Alcohol Clin Exp Res 24:611-621.

Tzourio-Mazoyer N, Landeau B, Papathanassiou D, Crivello F, Etard O, Delcroix N, Mazoyer B, Joliot M (2002) Automated anatomical labeling of activations in SPM using a macroscopic anatomical parcellation of the MNI MRI single-subject brain. Neuroimage 15:273-289.

Wan X, Takano D, Asamizuya T, Suzuki C, Ueno K, Cheng K, Ito T, Tanaka K (2012) Developing intuition: neural correlates of cognitive-skill learning in caudate nucleus. J Neurosci 32:17492-17501.

Wechsler D (2001) WAIS-III : Wechsler Adult Intelligence Scale, Third Edition. Canadian Technical Manual. Harcourt Canada, Toronto, ON.

Weingartner HJ, Andreason PJ, Hommer DW, Sirocco KY, Rio DE, Ruttimann UE, Rawlings RR, Eckardt MJ (1996) Monitoring the source of memory in detoxified alcoholics. Biol Psychiatry 40:43-53.

Winter WE, Broman M, Rose AL, Reber AS (2001) The assessment of cognitive procedural learning in amnesia: why the tower of Hanoi has fallen down. Brain Cogn 45:79-96.

Woltz DJ (1988) An investigation of the role of working memory in procedural skill acquisition. J Exp Psychol Gen 117:319-331.

World Health Organization (1980) Problems Related to Alcohol Consumption. Report of the Expert Committee. World Health Organization, Geneva.

Xu Y, Corkin S (2001) H.M. revisits the Tower of Hanoi puzzle. Neuropsychology 15:69-79. 